\title{
Pollock oil supplementation modulates hyperlipidemia and ameliorates hepatic steatosis in mice fed a high-fat diet
}

\author{
Zhi-Hong Yang ${ }^{*}$, Hiroko Miyahara, Jiro Takeo, Akimasa Hatanaka and Masashi Katayama
}

\begin{abstract}
Background: Hyperlipidemia associated with obesity is closely related to the development of atherosclerosis. Both n-3 polyunsaturated fatty acids (PUFAs) and long-chain monounsaturated fatty acids (MUFAs; i.e., C20:1 and C22:1 isomers) supplementation modulate risk factors for metabolic syndrome via multiple mechanisms, including the restoration of impaired lipid metabolism. We therefore examined the effects of pollock oil, which contains a considerable amount of n-3 PUFAs as well as long-chain MUFAs, on plasma hyperlipidemia and hepatic steatosis in diet-induced obese mice.

Methods: Male C57BL/6J mice (24-26 g) were divided into two groups ( $\mathrm{n}=10 / \mathrm{group}$ ) and were fed a high-fat diet containing 32\% lard (control group) or 17\% lard plus 15\% pollock oil (experimental group) for 6 weeks. For both groups, fat comprised $60 \%$ of the total caloric intake.

Results: Although body and liver masses for the two groups did not differ significantly, hepatic lipids concentrations (triglycerides and total cholesterols) were lower $(P<0.05)$ after pollock oil ingestion. After 2 weeks on the specified diets, plasma lipid levels (total cholesterol, LDL cholesterol, and triglycerides) significantly decreased $(P<0.05)$ in the experimental group compared with the control group, although plasma HDL cholesterol levels did not differ. At the end of 6 weeks, plasma adiponectin levels increased $(P<0.05)$, whereas plasma resistin and leptin levels decreased $(P<0.05)$ in the experimental mice. Increased levels of long-chain MUFAs and n-3 PUFAs in plasma, liver and adipose tissue by ingesting pollock oil were possibly correlated to these favorable changes. Expression of hepatic genes involved in cholesterol metabolism (SREBP2, HMGCR, and ApoB) and lipogenesis (SREPB1C, SCD-1, FAS, and ACaCa) was suppressed in the experimental group, and may have favorably affected hyperlipidemia and hepatic steatosis induced by the high-fat diet.

Conclusions: We demonstrated that pollock oil supplementation effectively improved hyperlipidemia, attenuated hepatic steatosis, and downregulated the express of hepatic genes involved in cholesterol and lipid metabolism in mice with diet-induced obesity.
\end{abstract}

Keywords: Pollock oil, n-3 PUFA, MUFA, hyperlipidemia, hepatic steatosis, adipokines

\section{Background}

Hyperlipidemia, a medical condition characterized by increased blood levels of lipids including cholesterol and triglycerides, is a critical component of metabolism syndrome as well as a possible predisposing factor for atherosclerosis, a leading cause of death worldwide $[1,2]$. Lipids that accumulate in the arterial wall as a

\footnotetext{
* Correspondence: yangzh@nissui.co.jp

Central Research Laboratory, Tokyo Innovation Center, Nippon Suisan Kaisha, Ltd., 32-3 Nanakuni 1 Chome Hachioji, Tokyo 192-0991, Japan
}

consequence of hyperlipidemia are oxidized and attract inflammatory monocytes, which differentiate into macrophages that take up the oxidized lipid. Oxidation of low-density lipoproteins (LDLs) in the arterial wall is a major and physiologically relevant mechanism for the pathogenesis of atherosclerosis, and the presence of lipid-loaded macrophage foam cells in the artery intima is a predictor for the development of atherosclerotic lesions. A close relationship exists between dietary fats and dyslipidemia-related events [3]. Although an
C Biomed Central

(c) 2011 Yang et al; licensee BioMed Central Ltd. This is an Open Access article distributed under the terms of the Creative Commons Attribution License (http://creativecommons.org/licenses/by/2.0), which permits unrestricted use, distribution, and reproduction in any medium, provided the original work is properly cited. 
increased intake of saturated fatty acids is pathogenic for coronary heart disease, numerous studies have demonstrated a protective effect of $n-3$ polyunsaturated fatty acids (PUFAs) through a variety of mechanisms, including reduction of triglycerides and very-low-density lipoproteins [4]. In addition, we have shown that marinederived long-chain monounsaturated fatty acids (MUFAs) (i.e., C20:1 and C22:1 isomers) modulate metabolic syndrome by restoring impaired glucose and lipid metabolism [5]. Therefore, fish oils that are rich in both n-3 PUFAs and long-chain MUFAs may help alleviate hypercholesterolemia and hypertriacylglyceridemia.

Alaska pollock (Theragra chalcogramma) is a North Pacific species of the cod family, Gadidae. Pollock oil contains considerable amounts of n-3 PUFAs and longchain MUFAs [6]. The Alaska pollock fishing industry is the largest in the United States and one of the largest in the world. In recent years, pollock fishing has accounted for $\sim 30 \%$ of all U.S. seafood landings by mass [7]. Although pollock oil is used in both the food and feed industries [8], little is known about the relationship between dietary pollock oil and hyperlipidemia. Given the health benefits of n-3 PUFAs and long-chain MUFAs, we examined the effect of dietary pollock oil on hyperlipidemia in mice with diet-induced dyslipidemia.

\section{Methods}

Measurement of fatty acid composition of dietary oils

Cameria lard was purchased from Romi Smilfood B. V. (Heerenveen, Netherlands). Pollock oil was obtained from Nippon Suisan Kaisha, Ltd. (Tokyo, Japan) and refined with silica gel and activated clays and then steam-distillation deodorized. All standard and extracted lipids were stored at $-20^{\circ} \mathrm{C}$ until used. Fatty acid compositions of the dietary fats (Table 1 ) were determined after methylation of samples with $14 \%(\mathrm{w} / \mathrm{v})$ boron trifluoride/methanol (Sigma Chemical Co., St. Louis, USA.) at $80^{\circ} \mathrm{C}$ for $30 \mathrm{~min}$. The resulting fatty acid methyl esters were quantified by gas chromatography using an Agilent 6890N Network Gas Chromatograph System (Agilent Technologies Japan, Ltd., Tokyo, Japan) equipped with a split injector, FID detector, and fused silica capillary column (DB-WAX, $30 \mathrm{~m} \times 0.25 \mathrm{~mm}$ I.D. $\times 0.25 \mu \mathrm{m}$ film thickness, J \& W Scientific, Agilent Technologies). Methyl esters were identified by comparison of retention times to those of fatty acid methyl ester standards (Nu-Chek Prep, Inc., Elysian, MN, USA). Pollock oil contains considerable levels of long-chain MUFAs and n-3 PUFAs (C20:1 as well as C22:1 isomers and n-3 PUFAs combined: 45\%).

\section{Animals and diets}

The Institutional Animal Care and Use Committee at Nihon Bioresearch Inc. (Gifu, Japan) approved this
Table 1 Fatty acid composition of dietary fats (\%)

\begin{tabular}{lll}
\hline \hline Fatty acid & Lard & Pollock oil \\
\hline $\mathrm{C} 14: 0$ & 1.5 & 4.9 \\
$\mathrm{C} 16: 0$ & 25.4 & 9.8 \\
$\mathrm{C} 16: 1$ & 2.4 & 6.1 \\
$\mathrm{C} 18: 0$ & 5.9 & 1.7 \\
$\mathrm{C} 18: 1$ & 40.6 & 14.3 \\
$\mathrm{C} 18: 2 \mathrm{n}-6$ & 10.8 & 1.3 \\
$\mathrm{C} 18: 3 \mathrm{n}-3$ & 1.0 & 1.1 \\
$\mathrm{C} 20: 1 \mathrm{n}-9$ & 0.8 & 9.1 \\
$\mathrm{C} 20: 1 \mathrm{n}-7$ & $\mathrm{ND}$ & 3.3 \\
$\mathrm{C} 22: 1 \mathrm{n}-11$ & $\mathrm{ND}$ & 12.3 \\
$\mathrm{C} 22: 1 \mathrm{n}-9$ & $\mathrm{ND}$ & 1.6 \\
$\mathrm{C} 20: 5 \mathrm{n}-3$ & 0.02 & 10.3 \\
$\mathrm{C} 22: 5 \mathrm{n}-3$ & 0.1 & 1.2 \\
$\mathrm{C} 22: 6 \mathrm{n}-3$ & 0.03 & 7.9 \\
\hline
\end{tabular}

Values correspond to mean of three separate samples processed independently.

ND: Not detected.

study. Male C57BL/6J mice (5 weeks old) were obtained from Charles River Laboratories Japan Inc. (Yokohama, Japan) and housed at Nihon Bioresearch at $23 \pm 1{ }^{\circ} \mathrm{C}$ under a 12/12 h light-dark cycle. The animals were provided free access to water and standard mouse chow CRF-1 (Oriental Yeast Co. Ltd., Tokyo, Japan) for a 1week acclimatization period.

After acclimatization, mice were randomly assigned to one of two groups for the 6-week feeding experiment. The control group $(\mathrm{n}=10)$ was fed a high-fat diet containing 32\% lard (D12492 Rodent Diet with 60 kcal\% Fat; Research Diets, Inc., NJ, USA) and the experimental group was fed a diet supplemented with pollock oil (17\% lard plus $15 \%$ pollock oil). To control for total fat intake, the total fat content in both diets corresponded to $60 \%$ of the caloric intake. The compositions of the diets are listed in Table 2. Body mass and food intake were monitored throughout the study. At the end of the intervention period, mice were

Table 2 Diet compositions

\begin{tabular}{lll}
\hline Ingredient & Lard diet $\mathbf{( g / 1 0 0 ~} \mathbf{g}$ diet) & PO diet $\mathbf{( g / 1 0 0 ~} \mathbf{g}$ diet $)$ \\
\hline Casein & 25.8 & 25.8 \\
I-Cysteine & 0.4 & 0.4 \\
Maltodextrin 10 & 16.2 & 16.2 \\
Sucrose & 8.9 & 8.9 \\
Cellulose & 6.5 & 6.5 \\
Mineral mixture & 1.3 & 1.3 \\
Vitamin mixture & 1.3 & 1.3 \\
Choline bitartrate & 0.3 & 0.3 \\
Soybean oil & 3.2 & 3.2 \\
Lard & 32 & 17 \\
Pollock oil & - & 15 \\
\hline
\end{tabular}

PO diet: Pollock oil-supplemented diet. 
anesthetized with $4 \%$ sodium pentobarbital (Dainippon Sumitomo Pharma, Osaka, Japan), and blood was collected by abdominal vein puncture. Plasma was obtained by centrifugation at $1000 \mathrm{~g}$ for $15 \mathrm{~min}$ and stored at $-80^{\circ} \mathrm{C}$ until analyses. Vital organs were removed and weighed after a short wash in cold phosphate-buffered saline, $\mathrm{pH}$ 7.4. Mesenteric white adipose tissue (WAT) and Livers were kept at $-80^{\circ} \mathrm{C}$ for the further lipid extraction and quantitative polymerase chain reaction (QPCR) analysis.

\section{Lipid extraction and fatty acid analysis}

The fatty acid compositions of plasma, liver and WAT in the $\mathrm{C} 57 \mathrm{BL} / 6 \mathrm{~J}$ mice were determined as described before [5]. Lipids were extracted by homogenizing the tissue samples in a methanol/hexane solution $(4: 1 \mathrm{v} / \mathrm{v})$ added with butylated hydroxytoluene (BHT, $50 \mu \mathrm{g} / \mathrm{mL}$ ) as an antioxidant. The samples were methylated with acetyl chloride, and the fatty acid methyl esters were separated and quantified by gas chromatography. Identification of the methyl esters were made by comparison of retention times of standard fatty acids.

\section{Determination of plasma lipid levels}

Blood samples were taken from the retro-orbital venous plexus of each mouse at the end of weeks $0,2,4$, and 6 . Plasma concentrations of triglyceride (TG), total cholesterol (TC), and high-density lipoprotein (HDL) cholesterol were measured using Triglycerol E-Test, Cholesterol ETest, and HDL-cholesterol E-Test kits (Wako Pure Chemical Industries, Ltd., Osaka, Japan), respectively. The concentration of LDL cholesterol was calculated as [LDL cholesterol $]=[\mathrm{TC}]-[$ HDL cholesterol $]-[\mathrm{TG}] \times 0.2$.

\section{Determination of plasma adipokine levels}

Plasma concentrations of adiponectin, resistin, and leptin were determined at the end of the 6-week period using the Mouse Adiponectin ELISA kit (Otsuka Pharmaceutical Co., Ltd., Tokyo, Japan), Mouse Resistin ELISA kit (Shibayagi Co. Ltd., Gunma, Japan), and Mouse Leptin ELISA kit (Morinaga Institute of Biological Science, Inc., Yokohama, Japan), respectively.

\section{Determination of hepatic lipid levels}

Total hepatic lipids were extracted from liver samples as described [9]. Extracted lipids were dried under vacuum (Concentrator Plus 5305, Eppendorf Inc., NY, USA) and then dissolved in 2-propanol containing 10\% (w/w) Triton X-100. Triglyceride and total cholesterol concentrations were determined using the above-mentioned commercial enzyme kits (Wako).

\section{Determination of mRNA expression by QPCR}

Total RNA was isolated from liver samples using TRIzol reagent (Qiagen, Valencia, CA, USA) according to the manufacturer's protocol. First-strand cDNA was generated from total RNA (1 $\mu \mathrm{g})$ using the PrimeScript II 1st strand cDNA Synthesis kit (TaKaRa Bio, Otsu, Japan). The resulting cDNA was used for QPCR amplification and specific sequence detection on an Applied Biosystems 7300 Real-Time PCR System (Life Technologies Ltd., Tokyo, Japan). The PCR cycling parameters were $30 \mathrm{~s}$ at $95^{\circ} \mathrm{C} ; 40$ cycles of $5 \mathrm{~s}$ at $95^{\circ} \mathrm{C}, 34 \mathrm{~s}$ at $60^{\circ} \mathrm{C}$; and a final melting curve of $15 \mathrm{~s}$ at $95^{\circ} \mathrm{C}, 1 \mathrm{~min}$ at $60^{\circ} \mathrm{C}, 15$ $\mathrm{s}$ at $95^{\circ} \mathrm{C}$. Gene expression was scaled to the expression of the housekeeping gene encoding $18 \mathrm{~S}$ ribosomal RNA. PCR reactions contained forward and reverse primers (10 $\mu \mathrm{M}$ each) and SYBR Premix Ex Taq (TaKaRa Bio). The targeted genes, their corresponding proteins, and the respective sense and antisense PCR primers were: SREBP2 (sterol regulatory element binding protein 2), 5'- TGGGCGATGAGCTGACTCT-3' and 5'- ACTGTAGCATCTCGTCGATGT-3'; HMGCR (3-hydroxy-3methylglutaryl-coenzyme A reductase), 5'- TGTTCACC GGCAACAACAAGA-3' and 5'-CCGCGTTATCGTCAGGATGA-3'; ApoB (apolipoprotein B), 5'-TTGGCA AACTGCATAGCATCC-3' and 5'-TCAAATTGGGACTCTCCTTTAGC-3'; ApoA (apolipoprotein A), 5'GGCACGTATGGCAGCAAGAT-3' and 5'-CCAAGGAGGAGGATTCAAACTG-3'; SREBP1c (sterol regulatory element binding protein 1c), 5'-GATGTGC GAACTGGACACAG-3' and 5'-CATAGGGGGCGTCAAACAG-3'; SCD-1 (stearoyl-coenzyme A desaturase1), 5'-TTCTTGCGATACACTCTGGTGC-3' and 5'CGGGATTGAATGTTCTTGTCGT-3'; FAS (fatty acid synthase), 5'-TTCTTGCGATACACTCTGGTGC-3' and 5'-CGGGATTGAATGTTCTTGTCGT-3'; Acac $\alpha$ (acetyl-coenzyme A carboxylase alpha), 5'-GATGAACCATCTCCGTTGGC-3' and 5'-CCCAATTATGAATC GGGAGTGC-3'.

\section{Statistical analysis}

Results are expressed as mean \pm standard error of the mean. Statistical differences between two groups were analyzed by Student's $t$-test and were considered significant at $P<0.05$.

\section{Results}

\section{Effect of pollock oil on body and organ mass}

Table 3 lists body and vital organ masses for dietinduced obese C57BL/6J mice in the control (lard) and experimental (pollock oil) groups. After the 6-week feeding period, there were no significant differences in body, liver, white as well as brown adipose tissue, and skeleton muscle masses between the two groups.

\section{Effect of pollock oil on plasma lipid levels}

Compared to control, total cholesterol plasma levels for the experimental group were reduced by $27 \%(P<0.01)$, 
Table 3 Food intake, body mass, and vital organ masses

\begin{tabular}{lll}
\hline \hline & Lard diet & PO diet \\
\hline Food intake (g/day) & $2.5 \pm 0.03$ & $2.3 \pm 0.04$ \\
Initial body mass (g) & $25.5 \pm 0.4$ & $25.5 \pm 0.5$ \\
Final body mass (g) & $32.7 \pm 1.6$ & $31.6 \pm 2.4$ \\
Organ masses (mg/g body mass) & & \\
$\quad$ Liver & $33.1 \pm 0.7$ & $33.6 \pm 0.7$ \\
$\quad$ Epididymal WAT & $50.9 \pm 3.0$ & $45.2 \pm 3.9$ \\
$\quad$ Mesenteric WAT & $15.4 \pm 0.9$ & $13.7 \pm 1.1$ \\
$\quad$ Brown adipose tissue & $3.3 \pm 0.5$ & $3.6 \pm 0.3$ \\
$\quad$ Skeletal muscle & $5.9 \pm 0.4$ & $5.9 \pm 0.3$ \\
\hline
\end{tabular}

Each value represents the mean \pm SE $(n=10)$. PO diet: Pollock oil-

supplemented diet; WAT: white adipose tissue.

17\% $(P<0.01)$, and 30\% $(P<0.001)$ at the end of weeks 2 , 4, and 6, respectively (Table 4 ). Pollock oil intake also significantly reduced plasma LDL cholesterol levels by 33\% $(P<0.05), 23 \%(P<0.01)$, and 38\% $(P<0.001)$, and reduced plasma triglyceride levels by $40 \%(P<$ $0.01), 50 \%(P<0.01)$, and $46 \%(P<0.01)$ at the end of weeks 2,4 , and 6 , respectively. No significant differences in plasma HDL cholesterol levels were detected.

Effect of pollock oil on fatty acid compositions of plasma, liver and WAT

Plasma, liver and mesenteric WAT fatty acid compositions in the control and pollock oil group are shown in Table 5 and Table 6 . Although total saturated fatty acid levels did not differ between the control and experimental group, pollock oil ingestion markedly $(P<0.05)$ increased long-chain MUFA (i.e., C20:1 and C22:1 isomers combined) levels 3-, 1.2- and 5-fold in plasma,

Table 4 Plasma levels of total cholesterol, LDL cholesterol, HDL cholesterol, and triglycerides

\begin{tabular}{lllll}
\hline \hline Lipids $(\mathrm{mg} / \mathrm{dL})$ & Week 0 & Week 2 & Week 4 & Week 6 \\
\hline $\begin{array}{l}\text { Total } \\
\text { cholesterol }\end{array}$ & & & & \\
$\quad$ Lard diet & $84.7 \pm 7.1$ & $154.5 \pm 10.5$ & $158.1 \pm 4.5$ & $161.5 \pm 4.3$ \\
$\quad$ PO diet & $80.8 \pm 6.0$ & $112.9 \pm 3.7^{* *}$ & $130.8 \pm 5.7^{* *}$ & $113.1 \pm 2.7^{* * *}$ \\
LDL & & & & \\
cholesterol & & & & \\
$\quad$ Lard diet & $39.1 \pm 7.0$ & $83.5 \pm 9.3$ & $87.7 \pm 3.4$ & $78.5 \pm 3.5$ \\
$\quad$ PO diet & $38.1 \pm 5.6$ & $56.1 \pm 3.1^{*}$ & $67.4 \pm 5.4^{* *}$ & $56.6 \pm 2.5^{* * *}$ \\
HDL & & & & \\
cholesterol & & & & \\
$\quad$ Lard diet & $34.6 \pm 2.0$ & $54.4 \pm 2.8$ & $51.4 \pm 2.0$ & $59.2 \pm 2.5$ \\
$\quad$ PO diet & $30.6 \pm 2.4$ & $47.3 \pm 1.8$ & $53.7 \pm 2.7$ & $43.7 \pm 3.4$ \\
Triglycerides & & & & \\
$\quad$ Lard diet & $56.4 \pm 4.4$ & $80.0 \pm 10.1$ & $95.7 \pm 12.9$ & $118.7 \pm 19.8$ \\
PO diet & $60.6 \pm 4.9$ & $47.7 \pm 6.7^{* *}$ & $48.2 \pm 6.8^{* *}$ & $63.9 \pm 5.7^{* *}$ \\
\hline
\end{tabular}

Each value represents the mean \pm SE $(n=10)$. PO diet: Pollock oilsupplemented diet; LDL: low-density lipoprotein; HDL: high-density lipoprotein; ${ }^{*} P<0.05 ;{ }^{* *} P<0.01$; ${ }^{* * *} P<0.001$.
Table 5 Fatty acid composition in plasma (\%)

\begin{tabular}{|c|c|c|}
\hline Fatty acid & Lard diet & PO diet \\
\hline $14: 0$ & $0.20 \pm 0.02$ & $0.29 \pm 0.02$ \\
\hline $16: 0$ & $13.95 \pm 0.33$ & $11.24 \pm 1.17$ \\
\hline 18:0 & $8.68 \pm 0.24$ & $6.80 \pm 0.86$ \\
\hline SAF & $22.84 \pm 0.47$ & $18.33 \pm 2.03$ \\
\hline $12: 1$ & $23.68 \pm 0.90$ & $24.71 \pm 1.84$ \\
\hline $16: 1$ & $0.69 \pm 0.10$ & $0.79 \pm 0.08$ \\
\hline $18: 1$ & $9.23 \pm 0.37$ & $7.77 \pm 0.52^{*}$ \\
\hline $20: 1 n-9$ & $0.18 \pm 0.01$ & $0.24 \pm 0.02^{*}$ \\
\hline $20: 1 n-7$ & ND & $0.22 \pm 0.02^{* * *}$ \\
\hline $22: 1 n-11$ & ND & $0.17 \pm 0.02^{* *}$ \\
\hline $22: 1 n-9$ & ND & $0.01 \pm 0$ \\
\hline MUFA & $33.77 \pm 0.97$ & $33.91 \pm 2.42$ \\
\hline $18: 2 n-6$ & $17.04 \pm 0.25$ & $10.81 \pm 1.13^{* *}$ \\
\hline $18: 3 n-6$ & $0.26 \pm 0.01$ & $0.08 \pm 0.01^{* * *}$ \\
\hline $20: 2 n-6$ & $0.13 \pm 0$ & $0.07 \pm 0.01^{*}$ \\
\hline $20: 3 n-6$ & $0.89 \pm 0.07$ & $0.29 \pm 0.04^{* * *}$ \\
\hline $20: 4 n-6$ & $14.03 \pm 0.57$ & $3.61 \pm 0.36^{* * *}$ \\
\hline $22: 4 n-6$ & $0.02 \pm 0$ & $0.02 \pm 0$ \\
\hline n-6 PUFA & $32.37 \pm 0.38$ & $14.87 \pm 1.54^{* * *}$ \\
\hline $18: 3 n-3$ & $0.18 \pm 0.02$ & $0.16 \pm 0.02$ \\
\hline $20: 5 n-3$ & $0.40 \pm 0.03$ & $6.32 \pm 0.81^{* *}$ \\
\hline $22: 5 n-3$ & $0.32 \pm 0.07$ & $4.71 \pm 1.76^{* *}$ \\
\hline $22: 6 n-3$ & $5.11 \pm 0.11$ & $11.62 \pm 2.04^{* *}$ \\
\hline n-3 PUFA & $6.01 \pm 0.11$ & $22.85 \pm 2.18^{* *}$ \\
\hline
\end{tabular}

Each value represents the mean \pm SE $(n=10)$. ND: Not detected; PO diet: Pollock oil-supplemented diet; SAF: saturated fatty acids; MUFA: monounsaturated fatty acids; PUFA: polyunsaturated fatty acids; ${ }^{*} P<0.05$; ${ }^{* *} P$ $<0.01 ;{ }^{* *} P<0.001$.

liver and WAT, respectively. Intake of pollock oil also significantly $(P<0.05)$ increased total n-3 PUFA levels 3-, 2- and 7-fold in plasma, liver and WAT, respectively. In contrast, total n-6 PUFA levels were significantly $(P<$ 0.05 ) decreased by $50 \%, 31 \%$ and $14 \%$ in plasma, liver and WAT, respectively in the pollock oil group as compared to the control.

\section{Effect of pollock oil on plasma adipocytokine levels}

To determine if pollock oil could relieve the adipokine dysregulation caused by excessive total caloric intake, we measured the adipokine plasma levels. Intake of pollock oil increased the plasma concentration of adiponectin by $15 \%(P<0.05)$ in the experimental group compared to the control group (Figure 1A). Plasma resistin and leptin concentrations were reduced by $14 \%$ $(P<0.05)$ and $41 \%(P<0.05)$, respectively (Figure $1 \mathrm{~B}$ and $1 C)$.

\section{Effect of pollock oil on hepatic steatosis}

Because obesity can trigger hepatic steatosis, which is associated with hyperlipidemia, we measured the levels of hepatic lipids to determine if pollock oil suppressed 
Table 6 Fatty acid composition in liver and mesenteric WAT (\%)

\begin{tabular}{|c|c|c|c|c|}
\hline \multirow[t]{2}{*}{ Fatty acid } & \multicolumn{2}{|l|}{ Liver } & \multicolumn{2}{|c|}{ Mesenteric WAT } \\
\hline & Lard diet & PO diet & Lard diet & $\mathrm{PO}$ diet \\
\hline 1:0 & $0.29 \pm 0.01$ & $0.30 \pm 0.01$ & $1.03 \pm 0.03$ & $1.85 \pm 0.03^{*}$ \\
\hline $5: 0$ & $21.47 \pm 0.13$ & $20.18 \pm 0.24^{* * *}$ & $20.43 \pm 0.11$ & $19.43 \pm 0.23^{* *}$ \\
\hline 8:0 & $8.09 \pm 0.13$ & $10.06 \pm 0.21^{* * *}$ & $4.39 \pm 0.11$ & $5.02 \pm 0.15^{* *}$ \\
\hline AF & $29.85 \pm 0.15$ & $30.55 \pm 0.17$ & $25.85 \pm 0.15$ & $26.29 \pm 0.22$ \\
\hline$: 1$ & 29 & $7.87 \pm$ & & $1.98 \pm 0.09$ \\
\hline 5:1 & $1.46 \pm 0.05$ & $1.25 \pm 0.07^{*}$ & & \\
\hline 18:1 & $22.55 \pm$ & $13.58 \pm$ & 45.71 & $37.42 \pm 0.33^{* * *}$ \\
\hline 20:1 n-9 & $0.51 \pm 0.02$ & $0.60 \pm 0.02^{* *}$ & $0.85 \pm 0.03$ & $3.12 \pm 0.13^{* * *}$ \\
\hline : 1 n-7 & ND & 0.41 & 0. & $* * * *$ \\
\hline 2:1 n-11 & ND & $0.19 \pm$ & $0.05 \pm 0$ & $8^{* * *}$ \\
\hline $2: 1$ n-9 & $0.06 \pm 0$ & $0.06 \pm 0.01$ & $0.04 \pm 0$ & $0.25 \pm 0.01^{* *}$ \\
\hline AUFA & $32.05 \pm 0.32$ & $23.86 \pm 0.51^{* * *}$ & $52.95 \pm 0.23$ & $49.63 \pm 0.51^{* *}$ \\
\hline $8: 2 n-6$ & $14.13 \pm 0.28$ & $11.89 \pm 0.16^{* * *}$ & $14.47 \pm 0.17$ & $12.70 \pm 0.28^{* * *}$ \\
\hline 18:3 n-6 & $0.29 \pm 0.01$ & $0.10 \pm 0.03^{* * *}$ & $0.07 \pm 0$ & $0.06 \pm 0.01$ \\
\hline $20: 2$ n-6 & $0.22 \pm 0$ & $0.12 \pm 0^{* * *}$ & $0.27 \pm 0$ & $0.17 \pm 0.03^{*}$ \\
\hline $20: 3 n-6$ & $0.86 \pm 0.04$ & $0.47 \pm 0.03^{* * *}$ & $0.12 \pm 0$ & $0.06 \pm 0^{* * *}$ \\
\hline $20: 4$ n-6 & $9.31 \pm 0.15$ & $4.66 \pm 0.09^{* * *}$ & $0.24 \pm 0.01$ & $0.15 \pm 0^{* * *}$ \\
\hline $22: 4$ n-6 & $0.31 \pm 0.01$ & $0.03 \pm 0^{* * *}$ & $0.07 \pm 0$ & $0.03 \pm 0^{* * *}$ \\
\hline n-6 PUFA & $25.11 \pm 0.18$ & $17.26 \pm 0.18^{* * *}$ & $15.23 \pm 0.17$ & $13.17 \pm 0.28^{* * *}$ \\
\hline $18: 3 n-3$ & $0.45 \pm 0.02$ & $0.56 \pm 0.03^{* *}$ & $0.07 \pm 0$ & $0.96 \pm 0.04^{* * *}$ \\
\hline $20: 5 n-3$ & $0.29 \pm 0.01$ & $4.84 \pm 0.17^{* * *}$ & $0.10 \pm 0$ & $0.73 \pm 0.05^{* * *}$ \\
\hline $22: 5 n-3$ & $0.51 \pm 0.01$ & $1.66 \pm 0.07^{* * *}$ & $0.11 \pm 0$ & $0.44 \pm 0.01^{* * *}$ \\
\hline $22: 6 n-3$ & $6.32 \pm 0.12$ & $15.36 \pm 0.26^{* * *}$ & $0.18 \pm 0$ & $1.42 \pm 0.04^{* * *}$ \\
\hline n-3 PUFA & $7.55 \pm 0.12$ & $22.42 \pm 0.18^{* * * *}$ & $0.45 \pm 0.01$ & $3.54 \pm 0.12^{* * *}$ \\
\hline
\end{tabular}

Each value represents the mean \pm SE $(n=10)$. ND: Not detected; WAT: white adipose tissue; PO diet: Pollock oil-supplemented diet; SAF: saturated fatty acids; MUFA: monounsaturated fatty acids; PUFA: polyunsaturated fatty acids; ${ }^{*} P<0.05 ;{ }^{*} P<0.01 ;{ }^{* *} P<0.001$.

hepatic lipid accumulation. Total hepatic lipid, triglyceride, and total cholesterol levels were reduced by $21 \%(P$ $<0.01), 40 \%(P<0.001)$, and $12 \%(P<0.05)$, respectively, in the experimental group compared with the control group (Figure 2).

\section{Effect of pollock oil on mRNA expression of genes involved in hepatic lipid metabolism}

The pollock oil-supplemented diet led to a $66 \%$ reduction $(P<0.001)$ in mRNA expression of $S R E B P 2$, a gene that encodes a transcription factor involved mainly in regulation of cholesterol synthesis (Figure 3A). It also reduced expression of the cholesterogenic gene $H M G C R$ by $51 \%$ $(P<0.05)$ and of $A p o B$ by $23 \%(P<0.05)$, although it had no significant effect on expression of ApoA. Furthermore, intake of pollock oil caused a $24 \%(P<0.05)$ reduction in mRNA expression of SREBP1c, which encodes for the lipogenic transcription factor SREBP1c, and also reduced expression of the downstream lipogenic genes $S C D-1$, FAS, and Acaca by $68 \%(P<0.001), 69 \%(P<0.001)$, and $33 \%(P<0.05)$, respectively (Figure $3 \mathrm{~B})$.

\section{Discussion}

People with obesity have an increased risk of cardiovascular disease, which is a major cause of their increased mortality. Although multiple factors are thought to contribute to these elevated risks, one main determinant is the adverse effect of obesity on lipoprotein levels [10]. For the study reported herein, we examined the effect of pollock oil on dyslipidemia in diet-induced obese mice, and showed that inclusion of pollock oil in a high-fat diet significantly decreased plasma levels of total and LDL cholesterol and triglyceride.

To identify possible mechanisms underlying this reduction, we measured plasma adipokine levels. Adiponectin, an adipocyte-derived hormone, is believed to play an important role in regulating hyperglycemia, hyperlipidemia, and endothelial dysfunction in humans, all of which probably contribute to certain markedly increased risks associated with obesity-related disorders, e.g., atherosclerosis and diabetes [11]. Adiponectin levels correlate negatively with serum triglyceride levels in non-diabetic subjects and type- 2 diabetics, and hypoadiponectinemia is associated with smaller LDL particle size, indicating a link between adiponectin and dyslipidemia [12-15]. Furthermore, in vitro data indicate that adiponectin is an anti-inflammatory and anti-proliferative mediator that can modulate atherosclerosis progression [16-18]. Conversely, increased levels of proinflammatory adipokines (e.g., tumor necrosis factor $\alpha$, resistin, monocyte chemotactic protein 1 , and interleukin 8) have been associated with increased serum lipids (e.g., triglycerides, and total and LDL cholesterol), which increase monocyte recruitment and adherence to arterial walls, causing wall remodeling [19-22]. In addition, leptin, the first adipocytokine discovered, has been associated with development of obesity, as $o b / o b$ leptindeficient mice are markedly obese [23]. However, most obese humans have increased blood leptin concentrations, likely reflecting resistance to the action(s) of leptin [24]. Leptin is also associated with increased insulin resistance, which can cause hyperlipidemia [25]. Therefore, the decreased plasma lipid concentrations observed following pollock oil ingestion were possibly associated with elevated plasma adiponectin levels and reduced plasma proinflammatory adipokine levels. As endogenous ligands for peroxisome proliferator-activated receptors, n-3 PUFAs regulate the expression of genes encoding key proteins involved in metabolism $[26,27]$. Intake of fish oil enriched in n-3 PUFAs has been reported to increase plasma adiponectin levels and lower proinflammatory adipokine levels $[28,29]$. Furthermore, we have shown that a diet rich in long-chain MUFAs modulates adipokine profiles [5]. Fatty acid composition analyses revealed that pollock oil ingestion 
A

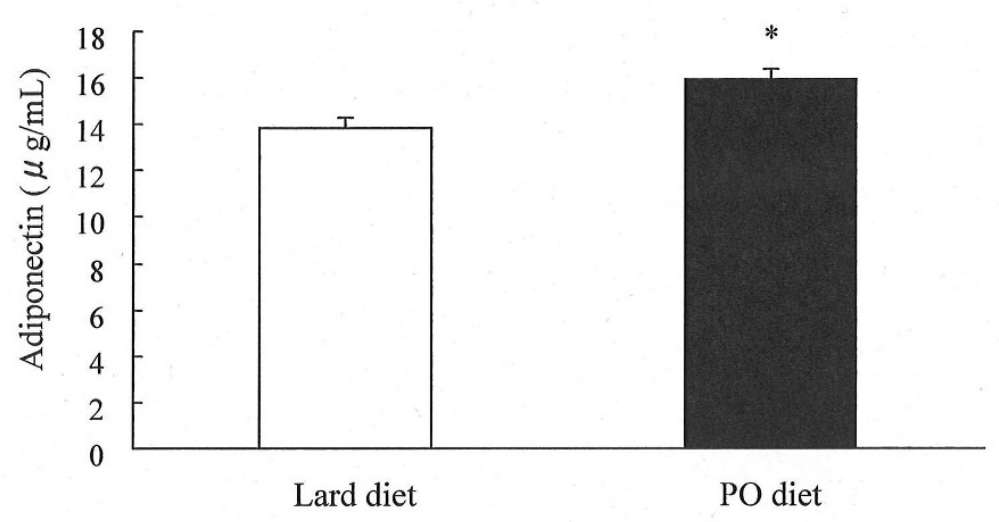

B

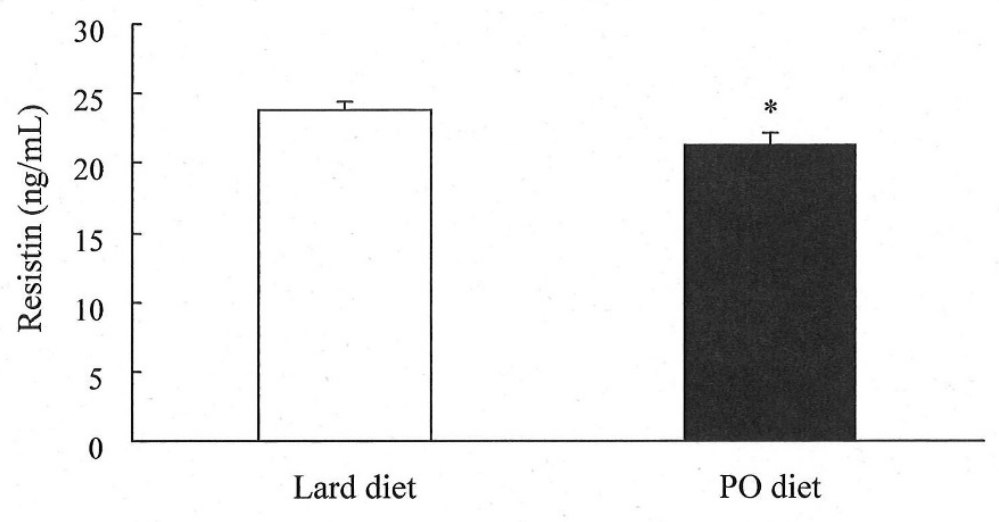

C

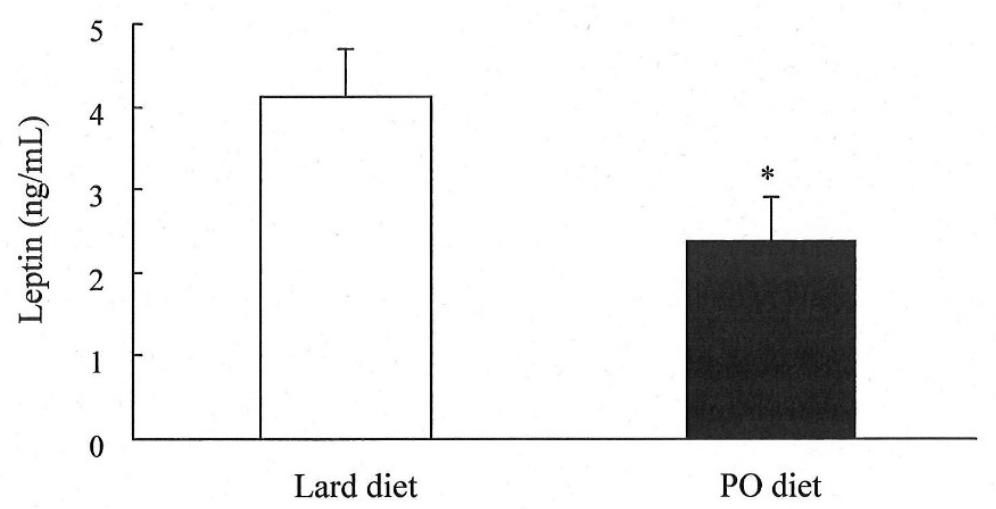

Figure 1 Effect of pollock oil on plasma adipokine levels in mice fed a high-fat diet. Plasma levels of adiponectin (A), resistin (B), and leptin (C) in C57BL/6J mice fed for 6 weeks with a diet containing 32\% lard (lard diet) or 17\% lard plus 15\% pollock oil (PO diet). Values are mean $\pm S E(n=10) .{ }^{*} P<0.05$. 

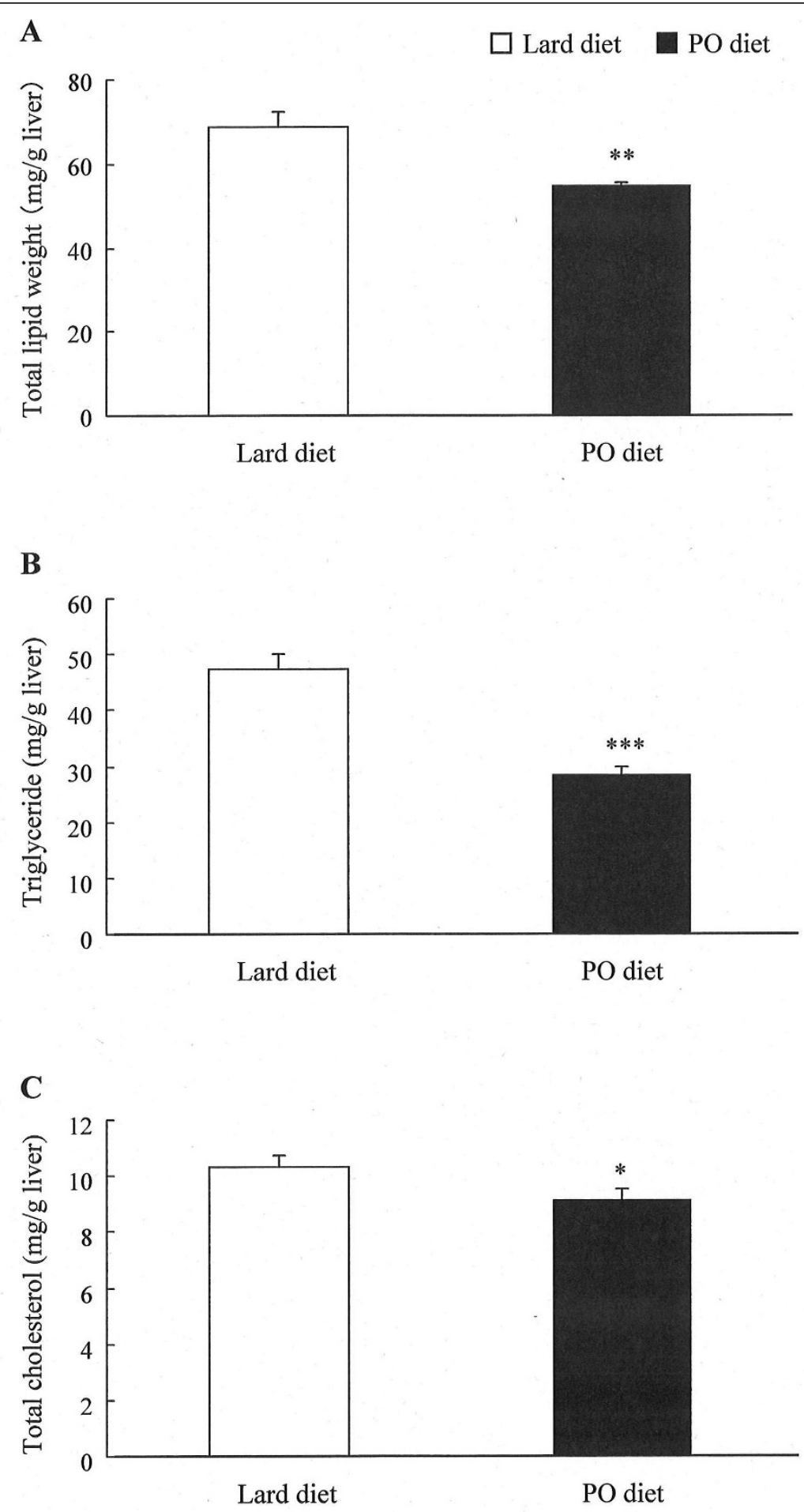

Figure 2 Effect of pollock oil on hepatic steatosis in mice fed a high-fat diet. Total hepatic lipid (A), triglyceride (B), and total cholesterol (C) levels in C57BL/6J mice fed for 6 weeks with a diet containing 32\% lard (lard diet) or 17\% lard plus 15\% pollock oil (PO diet). Values are mean \pm SE $(n=10) . * P<0.05 ; * * P<0.01 ; * * P<0.001$. 


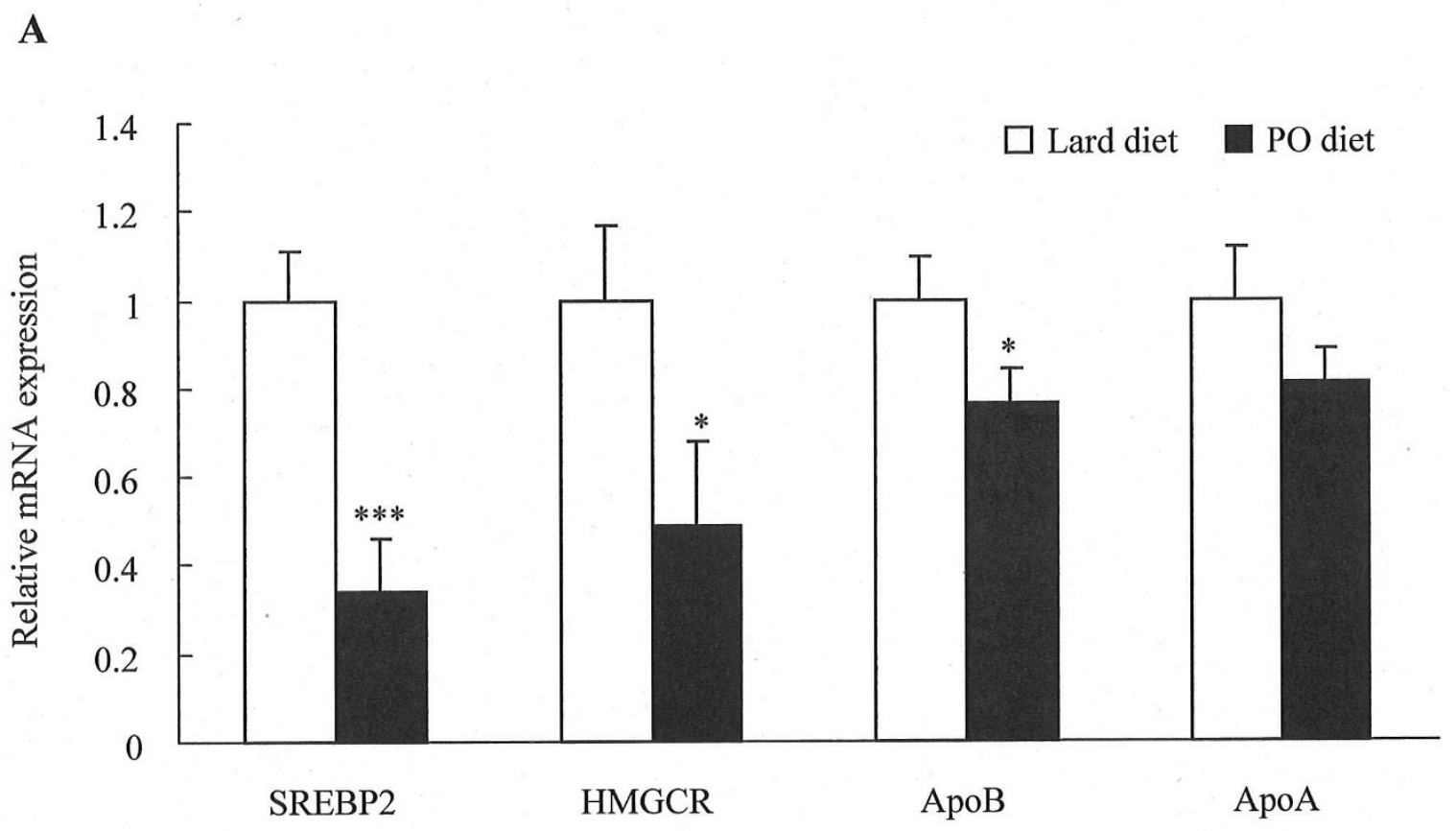

B

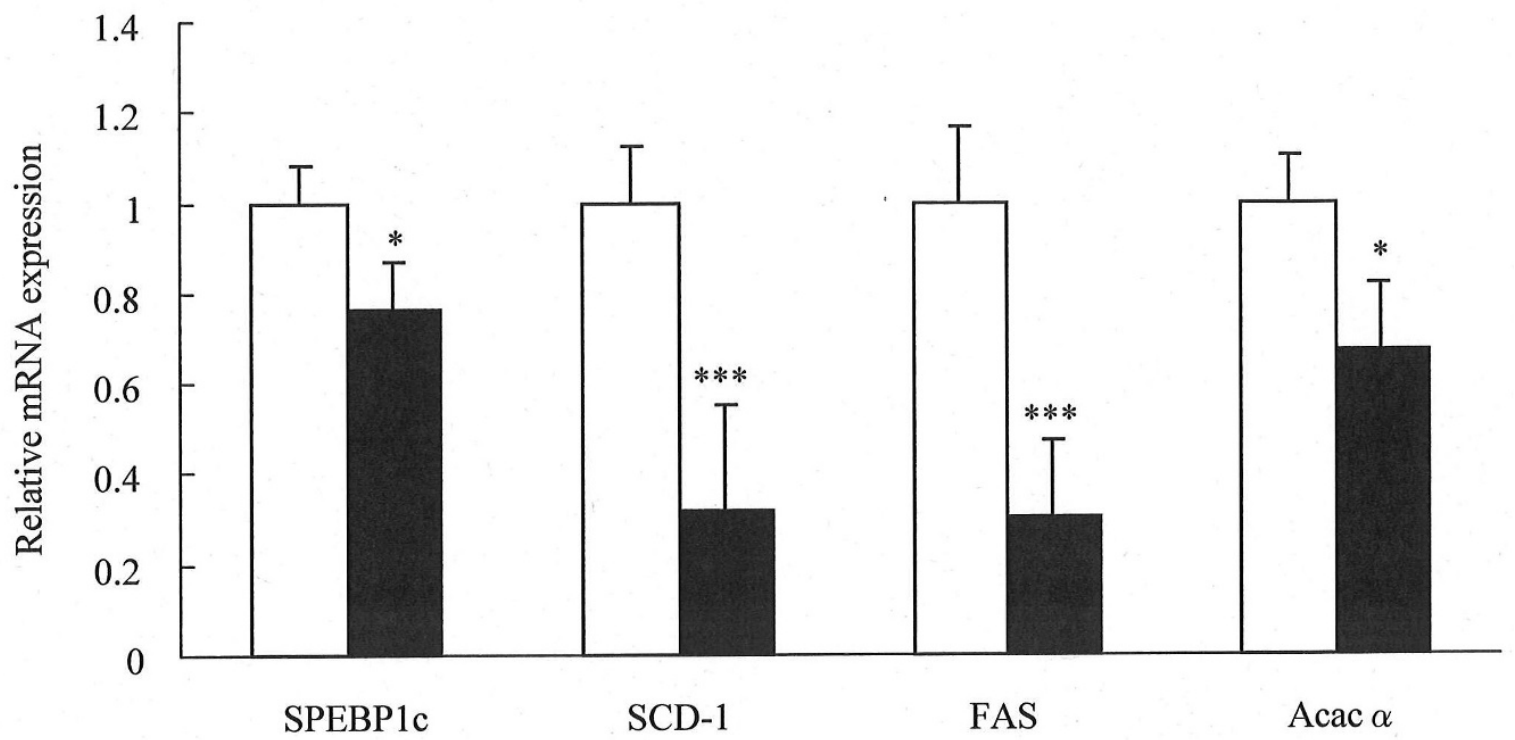

Figure 3 Effect of pollock oil on transcription of genes related to hepatic cholesterol and lipid metabolism. mRNA levels for genes involved in cholesterol (A) and lipid (B) metabolism in C57BL/6J mice fed for 6 weeks with a diet containing 32\% lard (lard diet) or 17\% lard plus $15 \%$ pollock oil (PO diet). Values are mean \pm SE $(n=10) .{ }^{*} P<0.05 ;{ }^{* * *} P<0.001$. 
significantly increased long-chain MUFA and n-3 PUFA levels in plasma and vital organs. Therefore, the favorable changes in the plasma adipokine profile might be attributed to a combined effect of n-3 PUFAs and longchain MUFAs found abundantly in pollock oil.

Ingestion of pollock oil also decreased hepatic lipid levels in the experimental group, indicating that pollock oil inhibited hepatic steatosis triggered by obesity. The liver is the most important organ in energy metabolism, and is vital to the production and catabolism of plasma lipoproteins and endogenous lipids [30,31]. The improvement in fatty filtration in the livers of pollock oil-fed mice was possibly related to the decreased plasma lipid levels. To characterize how pollock oil decreased hepatic lipid accumulation, we also determined the hepatic mRNA levels of genes related to lipid metabolism. In the liver, sterol regulatory element-binding proteins (SREBPs) are key transcription factors that regulate the levels of lipids produced for export into the plasma as lipoproteins and into the bile as micelles. The SREBP family includes SREBP1a, 1c, and 2 [32]. SREBP1c regulates transcription of genes involved in fatty acid metabolism (e.g., $S C D-1, F A S$, and Acaca), and SREBP2 regulates transcription of cholesterolrelated genes (e.g., $H M G C R$, which encodes the ratelimiting enzyme of cholesterol biosynthesis). Increased SREBP activity causes cholesterol and fatty acid accumulation and downregulates the SREBP-cleavage-activating protein (SCAP)/SREBP pathway by feedback inhibition [33]. Our data show that, concomitant with downregulation of SREBP1c and SREBP2 mRNA, intake of pollock oil suppressed transcription of genes targeted by SREBP. Furthermore, pollock oil intake inhibited hepatic $A p o B$ transcription. Apolipoprotein $B$ is central in lipoprotein metabolism [34], serving as a structural and functional component of triglyceride-rich very-low-density lipoproteins and their metabolic products, e.g., intermediatedensity lipoprotein and LDL. Downregulation of $A p o B$ expression may therefore decrease circulating LDL cholesterol levels. Notably, pollock oil ingestion did not alter mRNA expression of $A p o A$, the structural component of HDL, which may reflect the fact that plasma HDL cholesterol levels were the same in the control and experimental groups. Collectively, the observed decreases in mRNA levels suggest that the improvements in hepatic lipid levels and associated hyperlipidemia found in the experimental group may be partially associated with decreased de novo cholesterol, lipid, and ApoB synthesis.

\section{Conclusions}

Our study showed that ingestion of pollock oil ameliorated hypercholesterolemia and hypertriacylglyceridemia in diet-induced obese mice. The hypolipidemic effect of pollock oil was possibly related to an increase in plasma adiponectin concentrations and a decrease in the plasma levels of proinflammatory adipokines. Downregulation of mRNA expression of lipogenic genes and genes involved in cholesterol metabolism positively affected hepatic lipid accumulation, which likely led to an improved plasma lipid profile.

\section{List of abbreviations}

Acaca: acetyl-coenzyme A carboxylase alpha; ApoA: apolipoprotein A; ApoB: apolipoprotein B; FAS: fatty acid synthase; HDL: high-density lipoprotein; HMGCR: 3-hydroxy-3-methylglutaryl-coenzyme A reductase; LDL: low-density lipoprotein; MUFA: monounsaturated fatty acids; PUFA: polyunsaturated fatty acids; QPCR: quantitative polymerase chain reaction; SCD-1: stearoylcoenzyme A desaturase-1; SREBP: sterol regulatory element binding protein; WAT: white adipose tissue.

\section{Acknowledgements}

We thank Mr. Nobushige Doisaki and Ms. Kiyomi Furihata in Nippon Suisan Kaisha, Ltd. for technical assistance.

\section{Authors' contributions}

ZHY participated in the planning of the study, data analysis, and manuscript preparation. HM participated in experimental work. JT, AH and MK participated in the planning and organization of the study. All authors read and approved the final manuscript.

\section{Competing interests}

The authors declare that they have no competing interests.

Received: 21 September 2011 Accepted: 25 October 2011

Published: 25 October 2011

\section{References}

1. Holvoet P: Relations between metabolic syndrome, oxidative stress and inflammation and cardiovascular disease. Verh K Acad Geneeskd Belg 2008, 70:193-219.

2. Meydani M: Vitamin E and atherosclerosis: beyond prevention of LDL oxidation. J Nutr 2001, 131:366S-368S

3. Lairon D, Defoort C: Effects of nutrients on postprandial lipemia. Curr VasC Pharmacol 2011, 9:309-312.

4. Connor WE: n-3 Fatty acids and heart disease. In Nutrition and disease update: heart disease. Edited by: Kritchevsky D, Carroll KK. Champaign, IL: American Oil Chemists' Society; 1994:7-42.

5. Yang ZH, Miyahara H, Mori T, Doisaki N, Hatanaka A: Beneficial effects of dietary fish-oil-derived monounsaturated fatty acids on metabolic syndrome risk factors and insulin resistance in mice. J Agric Food Chem 2011, 59:7482-7489.

6. Oliveira ACM, Bechtel PJ: Lipid composition of Alaska pink salmon (Oncorhynchus gorbuscha) and Alaska walleye pollock (theragra chalcogramma). J Aquat Food Prod Tech 2005, 14:73-91.

7. Bailey KM, Powers DM, Quattro JM, Villa G, Nishimura A, Traynor JJ, Walters G: Population Ecology and Structural Dynamics of Walleye Pollock (Theragra chalcogramma). Dynamics of the Bering Sea 1999, 581-614.

8. Bimbo AP: Technology of production and industrial utilization of marine oil. In Marine biogenic lipids, fats, and oil. Volume II. Edited by: RG Ackman. Boca, Raton, Florida: CRC Press, Inc; 1989:401-433.

9. Folch J, Lees M, Stanley GHS: A simple method for the isolation and purification of total lipids from animal tissues. J Biol Chem 1956, 226:497-509.

10. National Heart, Lung, and Blood Institute: Clinical guidelines on the identification, evaluation, and treatment of overweight and obesity in adults-the evidence report. Obes Res 1998, 6(Suppl 2):51S-209S.

11. Chandran M, Phillips SA, Ciaraldi T, Henry RR: Adiponectin: more than just another fat cell hormone? Diabetes Care 2003, 26:2442-2450. 
12. Matsubara M, Maruoka S, Katayose S: Decreased plasma adiponectin concentrations in women with dyslipidemia. J Clin Endocrinol Metab 2002, 87:2764-2769

13. Kazumi T, Kawaguchi A, Hirano T, Yoshino G: Serum adiponectin is associated with high-density lipoprotein cholesterol, triglycerides, and low density lipoprotein particle size in young healthy men. Metab Clin Exp 2004, 53:589-593.

14. Hulthe J, Hulten LM, Fagerberg B: Low adipocyte-derived plasma protein adiponectin concentrations are associated with the metabolic syndrome and small dense low-density lipoprotein particles: atherosclerosis and insulin resistance study. Metab Clin Exp 2003, 52:1612-1614.

15. Schulze MB, Rimm EB, Shai I, Rifai N, Hu FB: Relationship between adiponectin and glycemic control, blood lipids, and inflammatory markers in men with type 2 diabetes. Diabetes Care 2004, 27:1680-1687.

16. Ouchi N, Kihara S, Arita Y, Nishida M, Matsuyama A, Okamoto Y, Ishigami M, Kuriyama H, Kishida K, Nishizawa H, Hotta K, Muraguchi M, Ohmoto Y, Yamashita S, Funahashi T, Matsuzawa Y: Adiponectin, suppresses lipid accumulation and class $\mathrm{A}$ scavenger receptor expression in human monocyte-derived macrophages. Circulation 2001, 103:1057-1063.

17. Yokota T, Oritani K, Takahashi I, Ishikawa J, Matsuyama A, Ouchi N, Kihara S, Funahashi T, Tenner AJ, Tomiyama Y, Matsuzawa Y: Adiponectin, a new member of the family of soluble defence collagens, negatively regulates the growth of myelomonocytic progenitors and the functions of macrophages. Blood 2000, 96:1723-1732.

18. Kumada M, Kihara S, Ouchi N, Kobayashi H, Okamoto Y, Ohashi K, Maeda K, Nagaretani H, Kishida K, Maeda N, Nagasawa A, Funahashi T, Matsuzawa Y: Adiponectin specifically increased tissue inhibitor of metalloproteinase-1 through interleukin-10 expression in human macrophages. Circulation 2004, 109:2046-2049.

19. Jovinge $S$, Hamsten A, Tornvall P, Proudler A, Bavenholm P, Ericsson CG Godsland I, de Faire U, Nilsson J: Evidence for a role of tumor necrosis factor alpha in disturbances of triglyceride and glucose metabolism predisposing to coronary heart disease. Metabolism 1998, 47:113-118.

20. Nelken NA, Coughlin SR, Gordon D, Wilcox JN: Monocyte chemoattractant protein-1 in human atheromatous plaques. J Clin Invest 1991, 88:1121-1127.

21. Stapleton PA, Goodwill AG, James ME, D'Audiffret AC, Frisbee JC: Differential Impact of Familial Hypercholesterolemia and Combined Hyperlipidemia on Vascular Wall and Network Remodeling in Mice. Microcirculation 2010, 17:47-58.

22. Tilg H, Moschen AR: Adipocytokines: mediators linking adipose tissue, inflammation and immunity. Nat Rev Immunol 2006, 6:772-783.

23. Ingalls AM, Dickie MM, Snell GD: Obese, a new mutation in the house mouse. J Hered 1950, 41:317-318.

24. Martin SS, Qasim A, Reilly MP: Leptin resistance: a possible interface of inflammation and metabolism in obesity-related cardiovascular disease. J Am Coll Cardiol 2008, 52:1201-1210.

25. Koh KK, Park SM, Quon MJ: Leptin and cardiovascular disease: response to therapeutic interventions. Circulation 2008, 117:3238-3249.

26. Berger J, Moller DE: The mechanisms of action of PPARs. Annu Rev Med 2002, 53:409-435.

27. Huss JM, Kelly DP: Nuclear receptor signaling and cardiac energetics. Circ Res 2004, 95:568-578.

28. Das UN, Ramos EJ, Meguid MM: Metabolic alterations during inflammation and its modulation by central actions of omega- 3 fatty acids. Curr Opin Clin Nutr Metab Care 2003, 6:413-419.

29. Browning LM: n-3 Polyunsaturated fatty acids, inflammation and obesityrelated disease. Proc Nutr Soc 2003, 62:447-453.

30. Shepherd J: Lipoprotein metabolism: an overview. Ann Acad Med Singapore 1992, 21:106-113.

31. Tietge UJ, Boker KH, Bahr MJ, Weinberg S, Pichlmayr R, Schmidt HH, Manns MP: Lipid parameters predicting liver function in patients with cirrhosis and after liver transplantation. Hepatogastroenterology 1998, 45:2255-2260.

32. Osborne TF: Sterol regulatory element-binding proteins (SREBPs): key regulators of nutritional homeostasis and insulin action. J Biol Chem 2000, 275:32379-32382

33. Goldstein $J$, Rawson RB, Brown MS: Mutant mammalian cells as tools to delineate the sterol regulatory element-binding protein pathway for feedback regulation of lipid synthesis. Arch Biochem Biophys 2002, 397:139-148
34. Burnett JR, Barrett PHR: Apolipoprotein B metabolism: tracer kinetics, models, and metabolic studies. Crit Rev Clin Lab Sci 2002, 39:89-137.

doi:10.1186/1476-511X-10-189

Cite this article as: Yang et al:: Pollock oil supplementation modulates hyperlipidemia and ameliorates hepatic steatosis in mice fed a high-fat diet. Lipids in Health and Disease 2011 10:189.

\section{Submit your next manuscript to BioMed Central and take full advantage of:}

- Convenient online submission

- Thorough peer review

- No space constraints or color figure charges

- Immediate publication on acceptance

- Inclusion in PubMed, CAS, Scopus and Google Scholar

- Research which is freely available for redistribution

Submit your manuscript at www.biomedcentral.com/submit
C Biomed Central 